\title{
Fabrication and performance of PET mesh enhanced cellulose acetate membranes for forward osmosis
}

\author{
Guoliang Li ${ }^{1,2,3}$, Jun Wang ${ }^{1,2, *}$, Deyin $\mathrm{Hou}^{1,2}$, Yu Bai ${ }^{1,2}$, Huijuan Liu ${ }^{1,2}$ \\ 1. Key Laboratory of Drinking Water Science and Technology, Research Center for Eco-Environmental Sciences, Chinese Academy of Sciences, \\ Beijing 100085, China. E-mail: glli_st@rcees.ac.cn \\ 2. Beijing Key Laboratory of Industrial Wastewater Treatment and Resource Recovery, Research Center for Eco-Environmental Sciences, \\ Chinese Academy of Sciences, Beijing 100085, China \\ 3. University of Chinese Academy of Sciences, Beijing 100049, China
}

\section{A R T I C L E I N F O}

Article history:

Received 7 August 2015

Revised 22 November 2015

Accepted 25 November 2015

Available online 6 February 2016

Keywords:

Forward osmosis

Cellulose acetate

Membrane

Water flux

Reverse salt flux

Internal concentration polarization

\begin{abstract}
A B S T R A C T
Polyethylene terephthalate mesh (PET) enhanced cellulose acetate membranes were fabricated via a phase inversion process. The membrane fabrication parameters that may affect the membrane performance were systematically evaluated including the concentration and temperature of the casting polymer solution and the temperature and time of the evaporation, coagulation and annealing processes. The water permeability and reverse salt flux were measured in forward osmosis (FO) mode for determination of the optimal membrane fabrication conditions. The optimal FO membrane shows a typical asymmetric sandwich structure with a mean thickness of about $148.2 \mu \mathrm{m}$. The performance of the optimal FO membrane was tested using $0.2 \mathrm{~mol} / \mathrm{L} \mathrm{NaCl}$ as the feed solution and $1.5 \mathrm{~mol} / \mathrm{L}$ glucose as the draw solution. The membrane displayed a water flux of $3.47 \mathrm{~L} /\left(\mathrm{m}^{2} \cdot \mathrm{hr}\right)$ and salt rejection of $95.48 \%$ in FO mode. While in pressure retarded osmosis (PRO) mode, the water flux was $4.74 \mathrm{~L} /\left(\mathrm{m}^{2} \cdot \mathrm{hr}\right)$ and salt rejection $96.03 \%$. The high ratio of water flux in FO mode to that in PRO mode indicates that the fabricated membrane has a lower degree of internal concentration polarization than comparable membranes.

C 2016 The Research Center for Eco-Environmental Sciences, Chinese Academy of Sciences.

Published by Elsevier B.V.
\end{abstract}

\section{Introduction}

Unlike applied pressure driven membrane processes such as nanofiltration (NF) and reverse osmosis (RO), which require intensive energy consumption, the forward osmosis (FO) process utilizes the osmotic pressure gradient as the driving force, and therefore is an energy-saving membrane separation technology. In a FO process, water transports across a selectively permeable membrane spontaneously from a region of higher water chemical potential (feed solution) to a region of lower water chemical potential (draw solution)
(Qin et al., 2012). This results in the concentration of the feed solution and dilution of the draw solution (Cath et al., 2006). It is traditionally believed that the FO process has the advantages of no or low pressure operation, higher water flux and recovery rate, less fouling propensity and easy cleaning (Chung et al., 2012; Duong and Chung, 2014). FO has received increased attention in the past decade in both academic research and industrial development (Shaffer et al., 2015). Although there are still considerable numbers of studies focusing on membrane preparation (Setiawan et al., 2011), characterization (Gao et al., 2013), and antifouling modifications (Wang et al., 2014),

\footnotetext{
* Corresponding author. E-mail: junwang@rcees.ac.cn (Jun Wang).
} 
nowadays increasing numbers of studies are beginning to be carried out on pilot scale and/or industrial level application (Altaee and Hilal, 2015; Hancock et al., 2013). As an environmentally friendly separation process, it has been widely studied in potential applications including wastewater treatment (Achilli et al., 2009; Zhao et al., 2015) and water purification (Cath et al., 2005; Duong and Chung, 2014), seawater desalination (Altaee et al., 2014; McCutcheon et al., 2006), food processing (Jiao et al., 2004; Petrotos and Lazarides, 2001), pharmaceutical applications (LaVan et al., 2003; Su and Lin, 2004), and power generation (Jia et al., 2014; Yip et al., 2011). The Modern Water Inc. (UK) has constructed seawater desalination plants based on the FO process, and Hydration Technology Innovation (HTI) has successfully developed a commercial product (SeaPack) for emergency water supply.

Despite the recent advancements in FO, there remain several challenges to overcome for successful widespread use of FO processes. Almost all the FO membranes suffer from severe internal concentration polarization (ICP). This is an important factor that hinders the application of FO, and is believed to be the main reason why the FO process has a much lower water flux than expected (McCutcheon et al., 2006). Early FO studies showed that ICP may be capable of reducing water flux by more than $80 \%$ (Mehta and Loeb, 1979). ICP is closely related with the thickness and porosity of the supporting layer (Gao et al., 2014). A thin membrane with a high porosity support layer has less potential for severe ICP. However, a thinner support layer results in weaker membrane mechanical strength. What's more, the traditionally believed advantages of FO may confront some more real-life problems. For example, Shaffer et al. (2015) draw the conclusion that FO cannot reduce the minimum energy required for desalination, regardless of the type of draw solution used. This is almost the reverse of the conclusions of most studies on the FO process, which reported that FO consumes less energy than the pressure-driven membrane processes (Venketeswari et al., 2014; Xie et al., 2012). Fabrication of an ideal membrane with high performance is still the main direction for FO development.

In recent years, numerous efforts have been made toward developing high-performance FO membranes with considerably higher water permeability than that of commercial FO membranes, by tuning the support layer structure and active layer characteristics (Liu et al., 2013; Wang et al., 2015; Zhao et al., 2014). Several materials have been used to fabricate FO membranes including cellulose triacetate (CTA), polyamide and biomimetic materials (Shibuya et al., 2015). Sairam et al. (2011) prepared a membrane containing a thin layer of cellulose acetate (CA) cast on a nylon fabric via a phase inversion process, using $\mathrm{MgSO}_{4}$ as the draw solution for desalination. Kim et al. (2013) fabricated a polyamide FO membrane with a newly synthesized acetylated methylcellulose (AMC) membrane as the support layer, and the membrane performed better than a polyamide RO membrane. Wang et al. (2010) prepared a CA FO membrane and showed that the second skin layer can significantly mitigate the adverse effects of ICP.

CA is a reasonably low cost and readily available material that has been successfully used in NF and RO membranes (Haddada et al., 2004; Idris et al., 2002). It also appears to be a good candidate for the fabrication of FO membranes with respect to the high water permeability. However, high reverse solute flux and a weak mechanical strength limit its application potential (Li et al., 2013). Polyethylene terephthalate mesh (PET) mesh can be a good candidate for strengthening the membrane mechanical properties. In this work, various CA membranes were fabricated via a phase inversion process and the optimized fabrication parameters were obtained. The effects of some fabrication parameters on the FO membrane performance were investigated. The performance of the membrane was tested using $\mathrm{NaCl}$ as the feed solution and glucose as the draw solution.

\section{Experimental}

\subsection{Materials and chemicals}

CA with an acylation degree of $39.2 \%$ was purchased from Sinopharm Chemical Reagent Co., Ltd. A mixture of N-methyl-2-pyrrolidone (NMP) and acetone was used as the solvent. Analytical grade sodium chloride, glucose, acetone and NMP were obtained from Sinopharm. Deionized (DI) water was used both in the coagulation process and for the membrane performance test.

\subsection{Polymer solution preparation and CA membrane fabrication}

The CA powder was dried overnight at $90^{\circ} \mathrm{C}$ in a vacuum oven to remove moisture. After cooling to room temperature, a certain amount of the dried polymer was added to a flask containing a premixed solvent of acetone (to obtain a constant concentration of $10 \mathrm{wt} . \%$ in the solution) and NMP. The flask sealed with cling film was subjected to continuous stirring on a rotator (IKA RV10 digital) at the speed of $20 \mathrm{rpm}$ until a homogenous solution was obtained. The solution was then stored at room temperature for 1 day to deaerate.

The fabrication involved in this work was conducted via a phase inversion process that has been reported in earlier works (Hou et al., 2009). Specifically, the polymer solution was spread evenly on the surface of a clean horizontal glass plate using a casting knife at a gate height of $200 \mu \mathrm{m}$. Then a tailored PET mesh (150-mesh) was placed on the surface of casting solution from the top carefully to avoid trapping any bubbles. The PET mesh was then embedded in the solution automatically due to capillarity. After evaporation for a few seconds, the whole composite was immediately immersed into a coagulation bath containing DI water at various temperatures to initiate phase separation. The resultant membrane was peeled off gently from the glass plate and was rinsed with flowing tap water overnight to remove the residual solvent. A hot water annealing process was then carried out at different temperatures for the purpose of structure adjustment of the membrane. The fabricated membranes were stored in DI water prior to use.

\subsection{Study of membrane morphology and strength}

The fabricated CA membrane was prone to deform and become brittle upon drying at room temperature. To mitigate the morphological transformation, the membranes were first 
stored in aqueous glycerol $(5 \% \mathrm{~V} / \mathrm{V})$ overnight. Then the wet membranes were transferred to a flask containing an appropriate amount of liquid nitrogen and dried by a Vacuum Freeze Dryer (FD-1A-50, Beijing Boyikang Corporation, China). A Hitachi E-1010 ion sputter device was employed to spread a thin gold layer on the surface and cross-section of the dried membranes. The structure and morphology of the flat-sheet membrane were inspected using Field Emission Scanning Electronic Microscopy (FESEM, Hitachi SU8020, Japan) (Wang et al., 2010).

The tensile stress-strain curves were measured using a tensile testing machine (HZ-1009 A, Shanghai Hengzhun Instrument Technology Co., LTD., China). Specifically, the membranes were first cut into I-shaped samples (Fig. 1) according to the GB13022-91. The clamps gripped both the wide ends. Then the sample was pulled at the speed of $10 \mathrm{~mm} / \mathrm{min}$. The testing temperature was maintained at $25^{\circ} \mathrm{C}$, and the data was collected using the M212C software.

\subsection{FO membrane performance test}

FO experiments were conducted using a lab-scale cross-flow filtration unit assembled and installed in the group, as shown in Fig. 2. The cross-flow permeation cell consists of two rectangular PMMA symmetric half-cells with a membrane pressed in between. Each half-cell is a $20 \mathrm{~mm}$ thick plate with an S-shaped rectangular channel $(33.5 \mathrm{~cm}$ in total length, $1.0 \mathrm{~cm}$ in width, and $0.5 \mathrm{~cm}$ in height) on one side. Two magnetic drive pumps (MP-30RZ) were used to circulate the feed and draw solutions, respectively. The velocities of flow along both sides of the membrane were the same $(0.33 \mathrm{~m} / \mathrm{sec}$, unless otherwise stated) in case any hydraulic pressure was generated. Both feed and draw solutions were maintained at $25^{\circ} \mathrm{C}$ by thermostatic baths. Both PRO and FO modes were tested under the same operating conditions. Each experiment was conducted for $2 \mathrm{hr}$ and repeated three times.

Water flux and the reverse salt flux from the draw solution to the feed were determined by a method reported elsewhere previously (McCutcheon et al., 2006; Wang et al., 2010). DI water $(1.5 \mathrm{~L})$ was used as the feed and $\mathrm{NaCl}$ aqueous solution $(1.5 \mathrm{~L}$ ) was used as the draw solution. Water flux was calculated by measuring the weight increase of the draw solution over a certain period after the water flux had stabilized for half an hour. The dilution of the draw solution was ignored since the ratio of water permeation flux to the volume of the draw solution was less than around 3\% during the measuring process. The rate at which the volume increases (determined from the weight change) divided by the membrane area yields the water flux $\left(\mathrm{J}_{w}, \mathrm{~L} /\left(\mathrm{m}^{2} \cdot \mathrm{hr}\right)\right)$

$J_{w}=\frac{\Delta m}{\rho \times S \times \Delta t}$

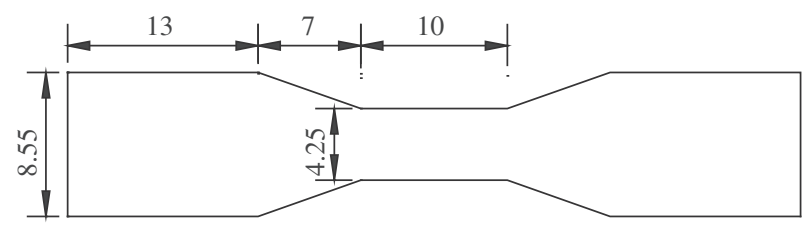

Fig. 1 - Sample shape for the tensile testing (in $\mathrm{mm}$ ). where $\Delta m(g)$ is the weight of water that permeates across the membrane in a predetermined time $\Delta t(\mathrm{hr})$ during the FO process and $S$ is the effective membrane surface area $\left(\mathrm{m}^{2}\right) . \rho$ is the density of water.

The reverse salt flux $\left(J_{s}, \mathrm{~g} /\left(\mathrm{m}^{2} \cdot \mathrm{hr}\right)\right)$ was calculated by measuring the salt concentration increase (determined from the conductivity change) of the feed solution over a given time interval.

$J_{\mathrm{s}}=\frac{C_{t} V_{t}-C_{0} V_{0}}{S \times \Delta t}$

where $C_{0}(\mathrm{~mol} / \mathrm{L})$ and $V_{\mathrm{o}}(\mathrm{L})$ are the initial salt concentration and the initial volume of the feed, respectively, while $C_{t}(\mathrm{~mol} / \mathrm{L})$ and $V_{t}(L)$ are the salt concentration and the volume of the feed at time $t$ during the FO tests, respectively. Specific reverse salt flux (SRSF), which is the ratio of reverse salt flux to permeate water flux $\left(J_{s} / J_{w}\right)$, reflects the membrane selectivity, FO efficiency and draw solute loss per unit permeate water product (Hancock and Cath, 2009). A high SRSF value indicates poor selectivity, low FO efficiency and high draw solute leakage to the feed side.

The salt rejection experiment was conducted using $0.2 \mathrm{~mol} / \mathrm{L}$ $\mathrm{NaCl}$ aqueous solution $(1.5 \mathrm{~L})$ as the feed and $1.5 \mathrm{~mol} / \mathrm{L}$ glucose solution $(1.5 \mathrm{~L})$ as the draw solution. Following the same operating procedure referred to above, the water and salt ions transport through the membrane to the draw side, thus raising the conductivity of the draw solution. The salt rejection was determined as follows:

$R=\left(1-\frac{C_{p}}{C_{f}}\right) \times 100 \%$

where $C_{f}$ and $C_{p}$ are the $\mathrm{NaCl}$ concentrations in the feed solution and in permeate water via diffusion through the membranes. $C_{p}$ was calculated by the amount of $\mathrm{NaCl}$ diffused into the draw solution divided by the water diffusing from the feed to the draw solution. The salt concentration was determined by the conductivity of the solution. The glucose cannot be hydrolyzed in the aqueous solution, and thus has almost no influence on the salt concentration determination (Li et al., 2013), which was also confirmed in this work.

\section{Results and discussion}

\subsection{Membrane characterization}

Fig. 3 shows the SEM image of the CA membrane fabricated under the optimal key parameters. The obtained membrane displays a typical asymmetric sandwich structure with a mean thickness of about $148.2 \mu \mathrm{m}$. The PET mesh was well embedded in the formed CA membrane. The top layer (Fig. 3a) is directly in contact with the water bath during the coagulation process, while the bottom layer (Fig. 3e) is in contact with the glass plate. The very compact structure in the upper half of the image (Fig. 3b) is the dense surface layer (Fig. 3a), which plays the main role in rejecting salts. The top dense surface layer (Fig. 3a) is more compact than the porous bottom layer (Fig. 3e), although both layers have different degrees of nodules. From the low magnification image of the top layer (the top-right corner of Fig. 3a), the uneven grille-like surface structure favors the 


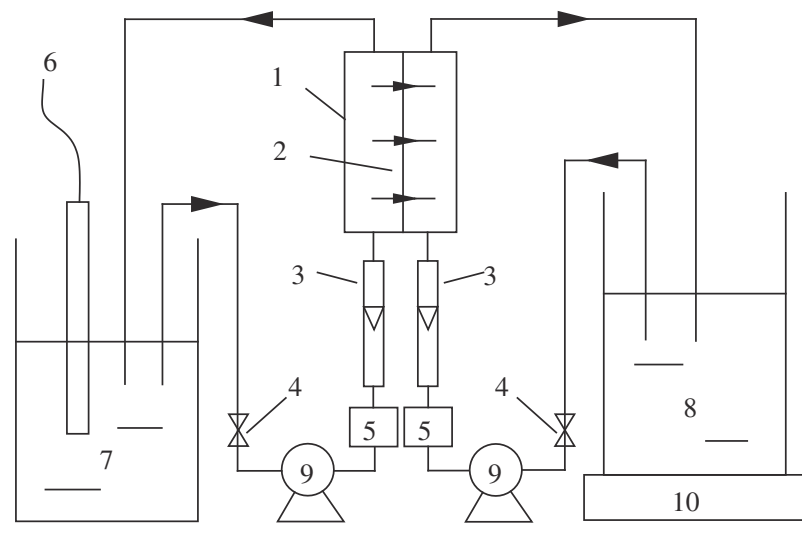

Fig. 2 - Schematic diagram of the lab scale FO system. (1) FO module; (2) FO membrane; (3) flow meter; (4) valves; (5) thermostat; (6) conductivity meter; (7) feed solution; (8) draw solution; (9) magnetic pump; (10) weighing scale. FO: forward osmosis. turbulence of fluid and reduces the ECP on the membrane surface even at a low velocity, and may lower the energy consumption. The middle sublayer, which occupies more than half of the whole thickness, consists of an upper half of tear-like voids and lower half with a large finger-like (Fig. 3c) and sponge-like porous structure (Fig. 3d). The large finger-like support structure ensures that the membrane not only has high water permeability, but also a low degree of ICP. The light spots are the salt crystals remaining on the membrane.

PET mesh is a good candidate for strengthening the membrane. It can greatly enhance the mechanical strength of CA membranes. In addition, it can make the membrane maintain a stable shape. We prepared two CA membranes for comparison, one with the PET mesh embedded and the other without PET. The tensile strain-stress curves and data are shown in Fig. 4 and Table 1. The CA membrane without the PET mesh embedded has an obvious yielding process from deformation of about 1-2.5 mm, while the CA membrane with PET embedded has no obvious yielding process. After PET was embedded, the brittle CA membrane became more flexible,
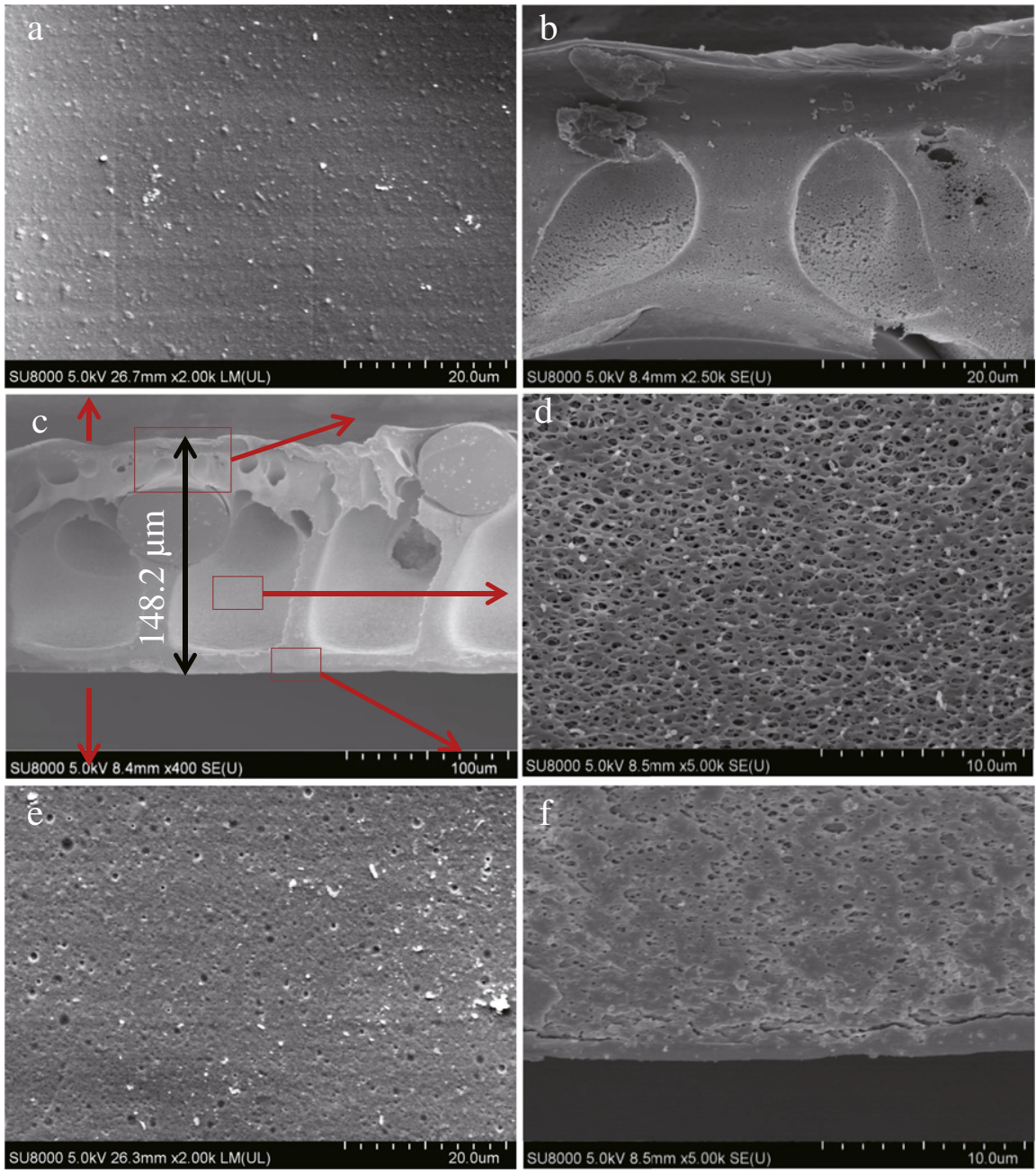

Fig. 3 - SEM images of the cellulose acetate membrane. (a) dense surface layer; (b) top part of cross-section at $\times 2.50 \mathrm{k}$ magnification; (c) whole cross-section at $\times 400$ magnification; (d) middle part of cross-section at $\times 5.00 \mathrm{k}$ magnification; (f) bottom part of cross-section atx $5.00 \mathrm{k}$ magnification; (e) porous bottom layer. 
with the elongation at break increased from $26.25 \%$ to $59.32 \%$. The membrane with the PET mesh embedded showed a much higher strength (tensile strength of $38.67 \mathrm{~N}$ ) than the membrane without PET embedded (tensile strength of $2.06 \mathrm{~N}$ ). The high tensile strength ensures that the PET mesh serves as a good mechanical support layer for the CA membrane.

\subsection{Effect of different parameters on the membrane performance}

\subsubsection{Effect of CA concentration}

Polymer solutions with different CA concentrations differ in viscosity, and hence may influence the phase inversion process. The effects of CA solutions with concentrations ranging from $15 \%$ to $20 \%$ on the water flux and salt reverse flux were investigated in this section (Fig. 5). Water flux decreased slightly as the CA concentration increased, while the reverse salt flux decreased very fast as the CA concentration increased to about 18 wt.\%. Hereafter, the reverse salt flux tended to a constant value of about $6.6 \mathrm{~g} /\left(\mathrm{m}^{2} \cdot \mathrm{hr}\right)$. The profile of SRSF is consistent with the trend of reverse salt flux, and no longer decreases at CA concentrations above $18 \mathrm{wt} . \%$. When the casting solution was immersed into the water, NMP and acetone diffused into water immediately and phase inversion took place. The phase inversion process resulted in a membrane with a dense layer on the water side, and a porous layer on the glass side. There are mainly three different kinds of pores on the membrane dense layer surface - the network pore, the aggregate pore and the phase separation pore (Zhu and Matsuura, 1991). As the CA concentration increases, the density of CA chains in the polymer solution increases, and the solution viscosity was observed to increase by nearly a factor of 6 (315 to $1905 \mathrm{cP}$ at $50^{\circ} \mathrm{C}$ with the shearing rate of $333 \mathrm{sec}^{-1}$ ) when the CA concentration increased only $5 \mathrm{wt} . \%$. The CA segments were prone to block each other, thus increasing the number of network pores and aggregate pores in the dense membrane layer surface, and reducing the number of the phase separation pores originating from the large polymer-poor phase (Sun, 2011). As a result, the mean pore size of the membrane surface became smaller and the water flux as well as the reverse salt flux being reduced. The membrane fabricated using a CA

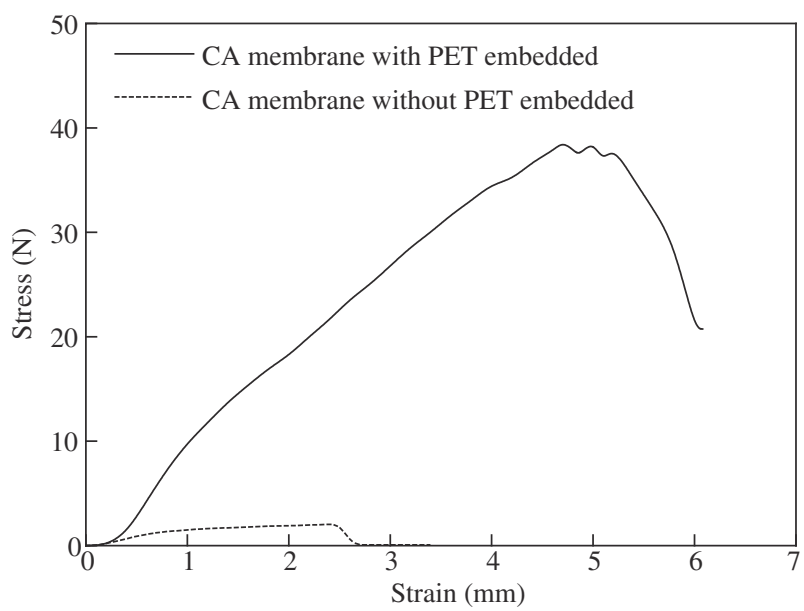

Fig. 4 - Comparison of tensile strain-stress curves of cellulose acetate membranes.
Table. 1-Tensile strain-stress characteristics of the cellulose acetate membranes.

$\begin{array}{cccc}\text { Samples } & \begin{array}{c}\text { Elongation } \\ \text { at break (\%) }\end{array} & \begin{array}{c}\text { Tensile } \\ \text { strength }(\mathrm{N})\end{array} & \begin{array}{c}\text { Offset yield } \\ \text { stress }(\mathrm{N})\end{array}\end{array}$

\begin{tabular}{lccc}
\hline $\begin{array}{l}\text { CA membrane without } \\
\text { PET mesh embedded }\end{array}$ & 26.25 & 2.06 & 1.68 \\
$\begin{array}{l}\text { CA membrane with } \\
\text { PET mesh embedded }\end{array}$ & 59.32 & 38.67 & 12.72 \\
\hline
\end{tabular}

solution with the concentration of $18 \mathrm{wt} . \%$ had both the available water flux and reverse salt flux of $6.3 \mathrm{~L} /\left(\mathrm{m}^{2} \cdot \mathrm{hr}\right)$ and $7.4 \mathrm{~g} /\left(\mathrm{m}^{2} \cdot \mathrm{hr}\right)$, respectively. Moreover, the membrane had the best selectivity properties with the relatively minimal SRSF of $1.2 \mathrm{~g} / \mathrm{L}$. In order to study the effect of different fabrication conditions on the permeate water flux and reverse salt flux, a CA solution with concentration of $18 \mathrm{wt}$.\% was used for the FO membrane preparation. Since the objective of this study was to optimize the fabrication conditions, the FO mode was adopted for the membrane performance tests in the following sections.

\subsubsection{Effect of the CA solution temperature}

The temperature not only affects the structure of polymer chain in the solution, but also the evaporation and subsequent coagulation process (Sun, 2011). As the temperature rises, the polymer chains are prone to rotate or stretch, and the free volume of the molecule chains increases. This increases the proportion of network pores and decreases the pore size of the dense layer, and resulting in a water flux decline and selectivity increase. However, the rising temperature accelerates the evaporation and coagulation processes. This will enhance the asymmetry of the membrane and raise the permeability. Therefore, the influence of the temperature on the membrane properties is a combined effect of the two conditions. In this part, the effect of solution temperature on the membrane performance was studied. The evaporation time was fixed at $60 \mathrm{sec}$ to assure that the CA solution temperature was the only factor influencing the membrane fabrication process. As can be seen from Fig. 6, water flux, reverse salt flux and the SRSF all increase as the temperature rises up to $55^{\circ} \mathrm{C}$. The obtained experimental results may be accounted for by the decline of the viscosity and density of the solution. Basically, both NMP and acetone are good solvents for CA. As the temperature rises in the investigated range, the CA molecule chains can more easily rotate or stretch, and the free volume of the molecule chains increases. At the same casting height, a casting solution with higher temperature has lower CA content. This result is consistent with the conclusion drawn from Section 2.2.1. Moreover, although the evaporation time was fixed at $60 \mathrm{sec}$ during the membrane fabrication process, increasing temperature inevitably accelerates the evaporation of the solvents and increases the coagulation rate. This will also raise the water flux and reverse salt flux. In summary, the temperature effect on the membrane properties is complex and not only affects the properties of the casting solution, but also the subsequent evaporation and coagulation processes.

\subsubsection{Effect of the evaporation process}

It has been reported that the layer structure of a membrane fabricated via the phase inversion process is dependent on 

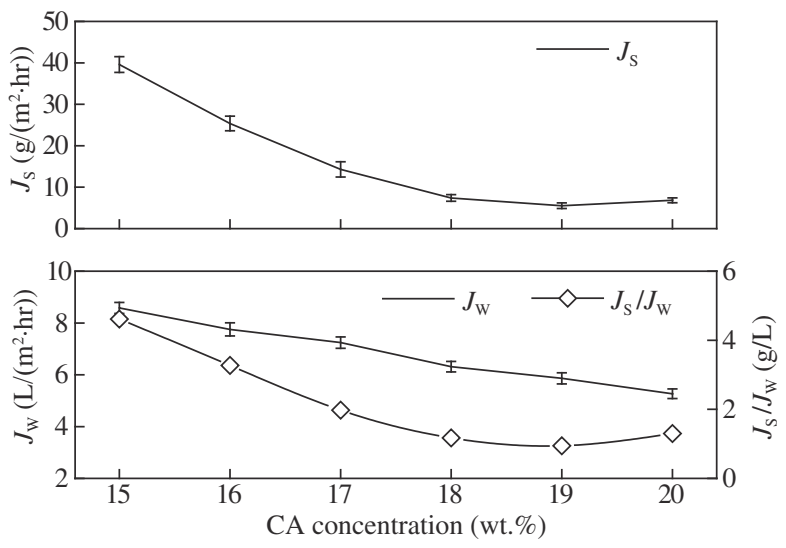

Fig. 5 - Effect of cellulose acetate concentration on the membrane performance. Fabrication conditions: polymer solution temperature at $25^{\circ} \mathrm{C}$, evaporation for $60 \mathrm{sec}$ at $50^{\circ} \mathrm{C}$, coagulation in $5^{\circ} \mathrm{C}$ DI water bath for $24 \mathrm{hr}$, post treatment at $70^{\circ} \mathrm{C}$ for $1 \mathrm{hr}$. For the membrane test: velocity and temperature of both feed and draw solutions of $0.33 \mathrm{~m} / \mathrm{sec}$ and $25^{\circ} \mathrm{C}$, respectively. DI water was used as the feed solution and $1 \mathrm{~mol} / \mathrm{L} \mathrm{NaCl}$ as the draw solution.

both the composition of the casting solution and the rate of the solvent evaporation (Sun, 2011). The evaporation process is of critical importance in the membrane fabrication process. Acetone is highly volatile and its evaporation process is influenced by environmental humidity, the evaporation temperature and time (Li et al., 2013). In this part, the evaporation temperature and time were taken into consideration to investigate their influence on the membrane performance. The ambient relative humidity of $70 \%$ was maintained throughout the evaporation process. Fig. 7a shows the effect of the evaporation temperature on membrane performance. With the increase of the evaporation temperature, the membrane water flux first increased to about $7 \mathrm{~L} /\left(\mathrm{m}^{2} \cdot \mathrm{hr}\right)$ at $62.5^{\circ} \mathrm{C}$, then had a slight decline to about $6.5 \mathrm{~L} /\left(\mathrm{m}^{2} \cdot \mathrm{hr}\right)$ at $100^{\circ} \mathrm{C}$. The reverse salt flux increases with a gradually slowing rate, while SRSF gradually increases in the range of 25 to $100^{\circ} \mathrm{C}$. Since the casting solution height is only $200 \mu \mathrm{m}$, the rising ambient temperature can easily raise the solution temperature. Hence, the effect of evaporation temperature on the membrane permeability is somewhat similar to the effect of solution temperature (Section 2.2.2). As the temperature rises, the evaporation of acetone increases the number of aggregation pores in the membrane surface. This will raise the water flux and reverse salt flux. When the evaporation temperature is higher than the acetone boiling point $\left(56^{\circ} \mathrm{C}\right)$, excessive evaporation of acetone results in pores coalescing, hence the numbers of pores decreases and the pore size increases (Li et al., 2013). The combination of the two effects makes the selectivity of the membrane decrease as the evaporation temperature increases.

Fig. $7 \mathrm{~b}$ shows the effect of the evaporation time on membrane performance. In the first $30 \mathrm{sec}$ of the evaporation process, the water flux maintains a steady value, while the reverse salt flux drops at a relatively high speed from about 11 to $9 \mathrm{~g} /\left(\mathrm{m}^{2} \cdot \mathrm{hr}\right)$. In the subsequent $30 \mathrm{sec}$, both water flux and reverse salt flux increase at different rates until the
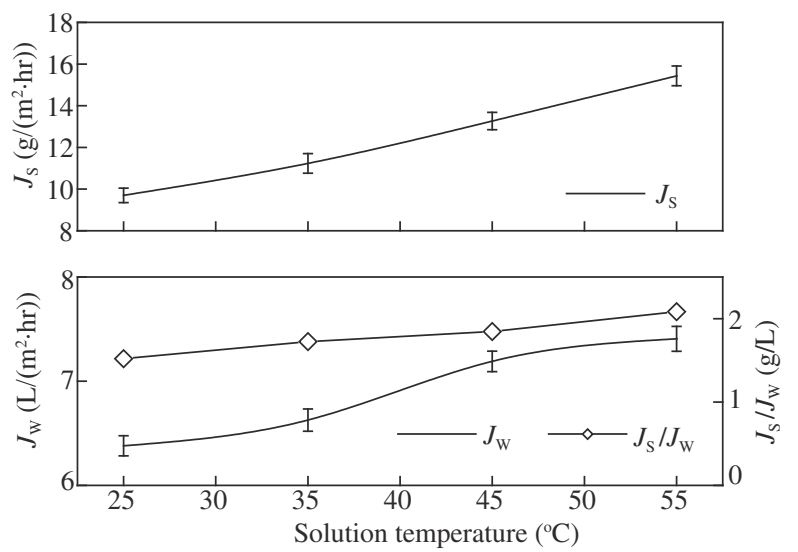

Fig. 6 - Effect of cellulose acetate solution temperature on the membrane performance. Fabrication conditions: CA content of $18 \mathrm{wt}$ \%, evaporation for $60 \mathrm{sec}$ at $50^{\circ} \mathrm{C}$, coagulation in $5^{\circ} \mathrm{C}$ DI water bath for $24 \mathrm{hr}$, post treatment at $70^{\circ} \mathrm{C}$ for $1 \mathrm{hr}$. For the membrane test: velocity and temperature of both feed and draw solutions of $0.33 \mathrm{~m} / \mathrm{sec}$ and $25^{\circ} \mathrm{C}$, respectively. DI water was used as the feed solution and $1 \mathrm{~mol} / \mathrm{L} \mathrm{NaCl}$ as the draw solution.

evaporation time reaches $60 \mathrm{sec}$. After that, both of them no longer change. Without the evaporation process, the forming membrane lacks a dense layer. This makes the membrane suffer from a severe ICP effect and results in a high reverse salt flux and relatively low water flux. As time goes by, an increasing amount of the solvent evaporates from the surface layer of the casting solution to the ambient air. This results in a dense surface layer with higher CA content than the bulk casting solution itself. When the coagulation process takes place, the casting solution with longer evaporation time will form a membrane more easily and rapidly with a dense surface layer. The forming dense layer enhances the asymmetry of the membrane and mitigates the ICP degree of the membrane surface layer, and raises the selectivity of the membrane. After evaporation for $60 \mathrm{sec}$, most of the solvent in the surface layer evaporates into the air and the forming dense layer greatly blocks the evaporation process. The membrane structure no longer changes and the permeability reaches a steady value.

\subsubsection{Effect of the coagulation process}

Coagulation is the main step that occurs in the phase inversion process. In this process, NMP and acetone act as the solvent and DI water as the nonsolvent. When the casting solution is immersed into the nonsolvent coagulation bath, interchange of solvent and nonsolvent due to diffusion causes the casting solution to go through a phase transition, and the membrane is formed (Young and Chen, 1993). It is well known that the coagulation bath temperature is a key parameter that affects the phase inversion thermodynamics and eventually the membrane structure. In this part, the effect of coagulation process on the membrane performance was studied. Fig. $8 \mathrm{a}$ shows the effect of coagulation temperature on the membrane permeability and selectivity. With the increase in water bath temperature from 5 to $25^{\circ} \mathrm{C}$, the membrane water flux decreased from 6.8 to $5.2 \mathrm{~L} /\left(\mathrm{m}^{2} \cdot \mathrm{hr}\right)$, while the reverse salt flux 

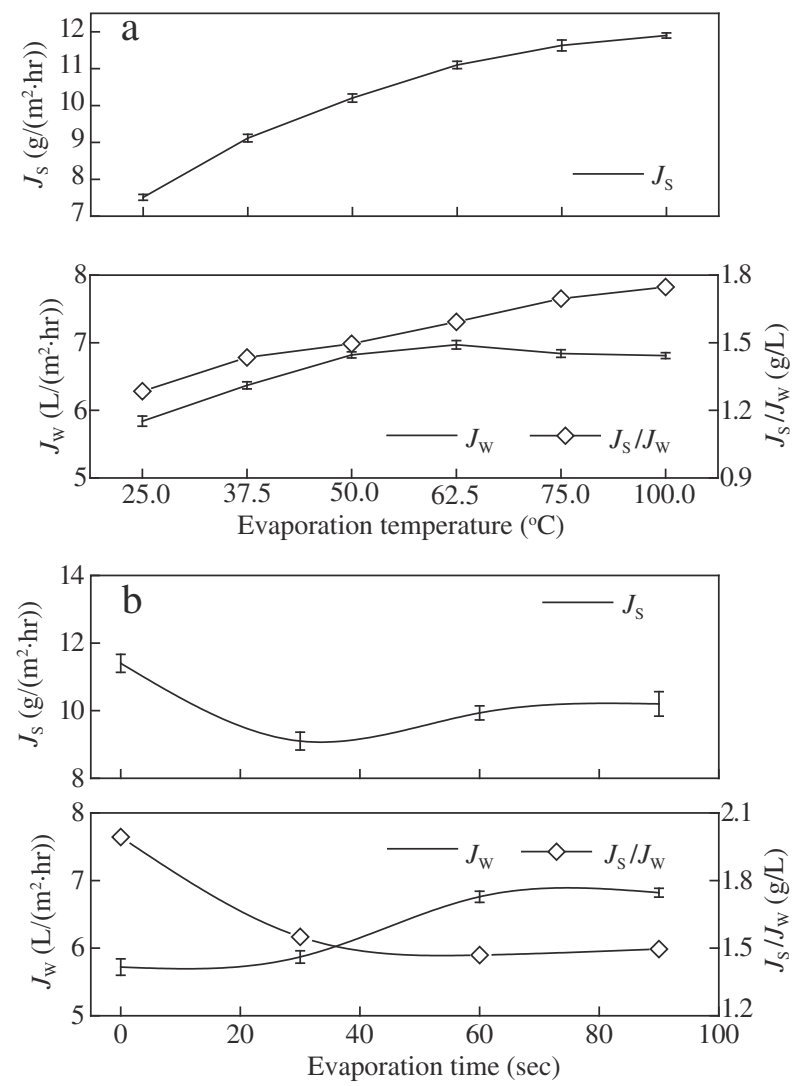

Fig. 7 - Effect of (a) evaporation temperature and (b) evaporation time on the membrane performance. Fabrication conditions: CA content of $18 \mathrm{wt} . \%$, polymer solution temperature at $25^{\circ} \mathrm{C}$, evaporation for $60 \mathrm{sec}(\mathrm{a})$ at $50^{\circ} \mathrm{C} \mathrm{(b),}$ coagulation in $5^{\circ} \mathrm{C}$ DI water bath for $24 \mathrm{hr}$, post treatment at $70^{\circ} \mathrm{C}$ for $1 \mathrm{hr}$. For the membrane test: velocity and temperature of both feed and draw solutions of $0.33 \mathrm{~m} / \mathrm{sec}$ and $25^{\circ} \mathrm{C}$, respectively. DI water was used as the feed solution and $1 \mathrm{~mol} / \mathrm{L} \mathrm{NaCl}$ as the draw solution.

remained at about 9 to $10 \mathrm{~g} /\left(\mathrm{m}^{2} \cdot \mathrm{hr}\right)$. The diffusion rate of solvent and nonsolvent at the interface of the casting solution and nonsolvent plays a key role in determining the membrane structure. Some works have drawn the conclusion that a higher coagulation rate promotes the formation of a loose finger-like membrane, while a lower coagulation process promotes formation of a dense sponge-like one (Frommer et al., 1970; Reuvers and Smolders, 1987; Reuvers et al., 1987; Rosenthal et al., 1971; Strathmann et al., 1975). Hence, a lower coagulation bath temperature may lead to a lower coagulation rate, which promotes the formation of a much denser layer than that at a higher coagulation temperature. The temperature of the coagulation bath affects not only the exchange rate of the solvent-nonsolvent, but also the motion of the polymer chains. Typically, a higher temperature favors the quick motion of the polymer chains, which enables the rearrangement of the polymer chains at the skin layer before the chains are completely fixed by gelation or glass transition. However, the detrimental effect is that high temperature results in lower water permeability. This phenomenon is consistent with the results reported by Su et al. (2010a). Fig. 8b shows the effect of coagulation time on the membrane performance. As the coagulation time increases, the membrane permeability gradually decreases, while the selectivity increases. As the casting solution was immersed into the coagulation bath, a dense layer immediately formed at the interface of the solution and coagulation bath due to the fast solvent diffusion into the water. The forming dense layer then inhibits the interchange of the water and solvent, and the diffusion process takes place at a gradually low rate. The diffusion rate becomes lower with increasing distance from the surface to the sublayer of the casting solution. With increasing coagulation time, the sublayer structure changes from loose finger-like to dense sponge-like and this results in a decrease in the permeability. Overall, to prepare a high flux CA membrane with relatively high performance, a water bath at a low temperature of $5^{\circ} \mathrm{C}$ for $24 \mathrm{hr}$ is preferred.

\subsubsection{Effect of the annealing process}

The as-formed membrane, which contains pores with large sizes and wide size distribution, is not stable without a thermal annealing process. This process has been reported to be an effective way to adjust or modify the pore structural characteristics of membranes (Su et al., 2010a,b). In this part, the effects of annealing temperature and time on the membrane performance were studied. Fig. 9a exhibits the effect of annealing temperature on the membrane performance. The annealing process can greatly enhance the selectivity of the membrane. The reverse salt flux of the casting membrane without any annealing treatment can be as high as 180 to $200 \mathrm{~g} /\left(\mathrm{m}^{2} \cdot \mathrm{hr}\right.$ ) (not shown in Fig. 9a due to the high value). With the increase of the annealing temperature from 50 to $70^{\circ} \mathrm{C}$, the water flux decreases gradually at a relatively low rate, and the reverse salt flux decreases rapidly from about 55.2 to $10.5 \mathrm{~g} /\left(\mathrm{m}^{2} \cdot \mathrm{hr}\right)$. At annealing temperatures higher than $70^{\circ} \mathrm{C}$, however, the water flux decreases gradually at a relatively high rate, and the reverse salt flux decreases from 9.9 to $3.6 \mathrm{~g} /\left(\mathrm{m}^{2} \cdot \mathrm{hr}\right)$. The membrane selectivity reaches a constant value when the temperature reaches at $70^{\circ} \mathrm{C}$ and no longer changes thereafter. Fig. 9b gives the profile of membrane performance versus annealing time. The membrane selectivity gradually increases with time, while an optimal permeability was observed at the annealing time of $1 \mathrm{hr}$.

The two obviously different rates of membrane permeability before and after the annealing temperature of $70^{\circ} \mathrm{C}$ may be accounted for by the glass transition temperature of CA (around $70^{\circ} \mathrm{C}$ ) (Chan et al., 1984; Wang et al., 1994). Before annealing, the CA nodules or CA nodule aggregates are loosely packed. Spaces between intramolecular CA chain segments (the Henry's mode sites) and large voids between nodule aggregates (the Langmuir sites) are relatively large as proposed by Kesting (1990). As the annealing temperature rises to $70^{\circ} \mathrm{C}$, the voids between nodule aggregates decrease, although a certain amount of incomplete nodule aggregates still exists in some domains. Annealing at temperatures higher than $70^{\circ} \mathrm{C}$ would cause a further shrinkage of the voids between nodule aggregates along with a slight reduction of the distance between intramolecular chains (Su et al., 2010a,b). Moreover, in the side chains of CA, most oxygen atoms of the carbonyl groups form intramolecular hydrogen bonds, which may be broken once the bonds absorb enough energy during 

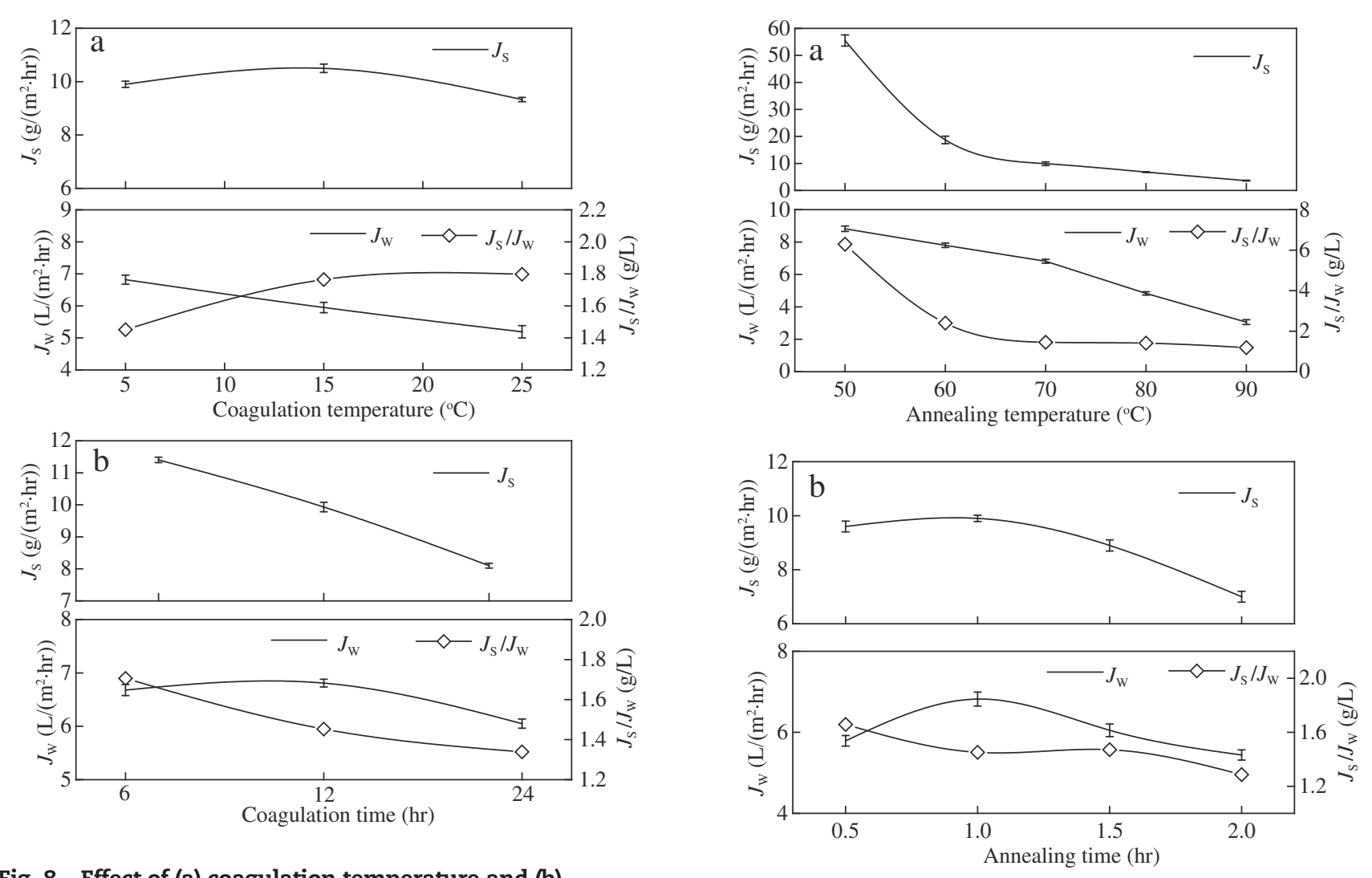

Fig. 8 - Effect of (a) coagulation temperature and (b) coagulation time operated on the membrane performance. Fabrication conditions: CA content of $18 \mathrm{wt} . \%$, polymer solution temperature at $25^{\circ} \mathrm{C}$, evaporation for $60 \mathrm{sec}$ at $50^{\circ} \mathrm{C}$, coagulation in $5^{\circ} \mathrm{C}$ (b) DI water bath for $24 \mathrm{hr}$ (a), post treatment at $70^{\circ} \mathrm{C}$ for $1 \mathrm{hr}$. For the membrane test: velocity and temperature of both feed and draw solutions of $0.33 \mathrm{~m} / \mathrm{sec}$ and $25^{\circ} \mathrm{C}$, respectively. DI water was used as the feed solution and $1 \mathrm{~mol} / \mathrm{L} \mathrm{NaCl}$ as the draw solution.

the annealing process. The carbonyl groups then have more freedom to rotate as single bonds. This enhances the possibility for the macromolecular chains or segments from different CA molecules to get closer to each other and form intermolecular hydrogen bonds (Duarte et al., 2007; Halary et al., 1980; Schwarz et al., 1987; Wasilewski, 1966). A higher packing density of the CA macromolecular chains or segments thus results from the heat treatment process. Overall, the annealing temperature of $70^{\circ} \mathrm{C}$ for $1 \mathrm{hr}$ was adopted as the optimal post-treatment condition.

\subsection{Performance of the optimal CA membrane}

The optimal CA membrane fabrication parameters were determined according to the studies discussed above. A commercial FO membrane has been developed by Hydration Technologies Inc. (HTI), which was believed to be made of a mixture of CTA and its derivatives. It is usually adopted as a reference for new FO membrane fabrication. In this section, the performance of the membrane fabricated was tested in comparison with the HTI membrane. The permeability and salt rejection of the membrane were tested using $0.2 \mathrm{~mol} / \mathrm{L}$

Fig. 9 - Effect of (a) annealing temperature and (b) annealing time operated on the membrane performance. Fabrication conditions: CA content of $18 \mathrm{wt} . \%$, polymer solution

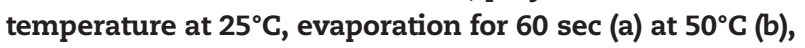
coagulation in $5^{\circ} \mathrm{C}$ DI water bath for $24 \mathrm{hr}$, post treatment at $70^{\circ} \mathrm{C}$ (b) for $1 \mathrm{hr}$ (a). For the membrane test: velocity and temperature of both feed and draw solutions of $0.33 \mathrm{~m} / \mathrm{sec}$ and $25^{\circ} \mathrm{C}$, respectively. DI water was used as the feed solution and $1 \mathrm{~mol} / \mathrm{L} \mathrm{NaCl}$ as the draw solution.

$\mathrm{NaCl}$ as the feed solution and $1.5 \mathrm{~mol} / \mathrm{L}$ glucose as the draw solution. As can be seen in Fig. 10, for the CA membrane, the PRO mode has a higher water flux $\left(4.74 \mathrm{~L} /\left(\mathrm{m}^{2} \cdot \mathrm{hr}\right)\right)$ and salt rejection $(96.03 \%)$ than those in FO mode of $3.47 \mathrm{~L} /\left(\mathrm{m}^{2} \cdot \mathrm{hr}\right)$ and $95.48 \%$, respectively. However for the HTI membrane, the PRO mode has a higher water flux $\left(7.93 \mathrm{~L} /\left(\mathrm{m}^{2} \cdot \mathrm{hr}\right)\right)$ and salt rejection (97.03\%) than those in FO mode of $3.41 \mathrm{~L} /\left(\mathrm{m}^{2} \cdot \mathrm{hr}\right)$ and $95.28 \%$, respectively. The differences in both permeability and salt rejection between the two modes can be accounted for by the asymmetric structural membrane orientations, which result in the different degrees of ICP within the membrane.

In FO mode, the permeate water dilutes the glucose solution concentration within the porous support layer and dilutive ICP occurs. This greatly decreases the effective osmotic pressure and reduces the water flux. By contrast, in $\mathrm{PRO}$ mode, $\mathrm{NaCl}$ solute accumulates within the support layer and concentrated ICP occurs. The degree of this ICP is much lower than that in FO mode due to the much lower osmotic pressure of the feed solution than the draw solution. Hence, the water flux in PRO mode is generally higher than that in FO mode (Cui et al., 2014). It has been reported that the higher the 

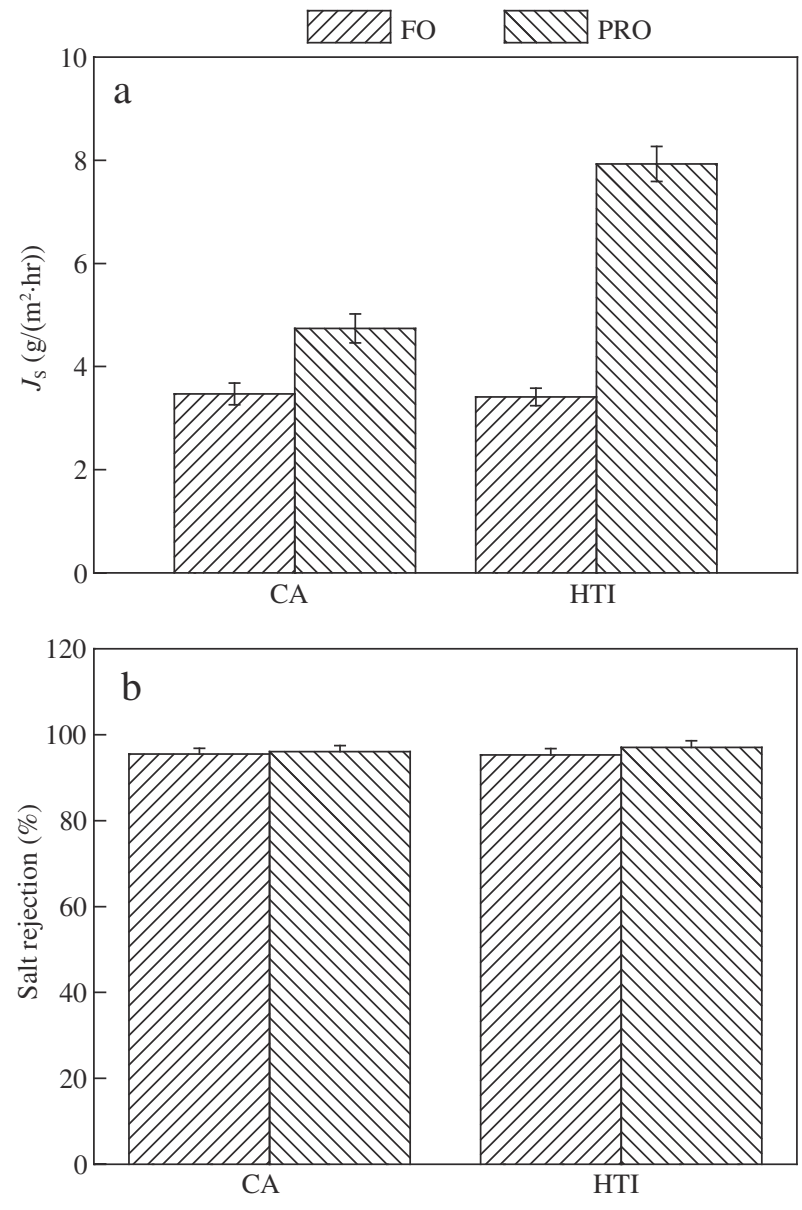

Fig. 10 - Comparison of cellulose acetate membrane with the HTI FO membrane. (a) water flux; (b) salt rejection. The test was carried out as follows: $0.2 \mathrm{~mol} / \mathrm{L} \mathrm{NaCl}$ as the feed solution, and $1.5 \mathrm{~mol} / \mathrm{L}$ glucose as the draw solution. Velocity and temperature of both feed and draw solutions of $0.33 \mathrm{~m} / \mathrm{sec}$ and $25^{\circ} \mathrm{C}$, respectively.

ratio of water flux in FO mode to that in PRO mode, the lower the degree of ICP (Li et al., 2013). In this work, the ratio of water flux in FO mode to that in PRO mode is $73.2 \%$. This result indicates the fabricated membrane has a lower degree of ICP compared with the previous studies of CTA membranes (50\%) and HTI membranes (40\%) (Li et al., 2013), which have been demonstrated to be good performing membranes. This ensures that the membrane has promising application potential. However, we cannot neglect the lower water flux of the CA membrane than that of the HTI's membrane in PRO mode, which may be due to the thicker membrane in this work $(148.2 \mu \mathrm{m})$ than the HTI membrane (about $80 \mu \mathrm{m}$ ). Considering this, we are now working on preparation of thinner membranes, which may raise the water flux while maintaining the high salt rejection.

\section{Conclusions}

In this study, a series of membranes were fabricated via a phase inversion method. The optimal key parameters for fabricating a FO membrane included a spreading height of $200 \mu \mathrm{m}$ for a solution with $18 \mathrm{wt} . \%$ of CA, as well as the processes of evaporating at $25^{\circ} \mathrm{C}$ for $60 \mathrm{sec}$, coagulating in a water bath at $5^{\circ} \mathrm{C}$ for $24 \mathrm{hr}$ and annealing at $70^{\circ} \mathrm{C}$ for $1 \mathrm{hr}$. The SEM analysis showed that the membrane enhanced by PET mesh had a grille-like dense top surface and a porous bottom layer. Both large finger-like and sponge-like structures existed in the sublayer, which ensured the membrane a low degree of ICP. The PET-enhanced CA membrane showed strong mechanical strength with tensile strength of $38.67 \mathrm{~N}$. The membrane showed both high water flux and salt rejection, and the PRO mode performed better than the FO mode. In addition, the membrane had a lower degree of ICP than comparable membranes, which ensures that the membrane has promising application potential.

\section{Acknowledgments}

The authors would like to acknowledge the financial support of the National Natural Science Foundation of China (Nos. 51378491, 21307149).

\section{R E F E R E N C E S}

Achilli, A., Cath, T.Y., Marchand, E.A., Childress, A.E., 2009. The forward osmosis membrane bioreactor: a low fouling alternative to MBR processes. Desalination 239, 10-21.

Altaee, A., Mabrouk, A., Bourouni, K., Palenzuela, P., 2014. Forward osmosis pretreatment of seawater to thermal desalination: high temperature FO-MSF/MED hybrid system. Desalination 339, 18-25.

Altaee, A., Hilal, N., 2015. High recovery rate NF-FO-RO hybrid system for inland brackish water treatment. Desalination 363, $19-25$.

Cath, T.Y., Adams, D., Childress, A.E., 2005. Membrane contactor processes for wastewater reclamation in space: II. Combined direct osmosis,osmotic distillation, and membrane distillation for treatment of metabolic wastewater. J. Membr. Sci. 257, 111-119.

Cath, T.Y., Childress, A.E., Elimelech, M., 2006. Forward osmosis: principles, applications, and recent developments. J. Membr. Sci. 281, 70-87.

Chan, K., Tinghui, L., Matsuura, T., Sourirajan, S., 1984. Effect of shrinkage on pore-size and pore-size distribution of cellulose-acetate reverse-osmosis membranes. Ind. Eng. Chem. Prod. Res. Dev. 23, 124-133.

Chung, T.S., Zhang, S., Wang, K.Y., Su, J.C., Ling, M.M., 2012. Forward osmosis processes: yesterday, today and tomorrow. Desalination 287, 78-81.

Cui, Y., Ge, Q.C., Liu, X.Y., Chung, T.S., 2014. Novel forward osmosis process to effectively remove heavy metal ions. J. Membr. Sci. 467, 188-194.

Duarte, A.P., Bordado, J.C., Cidade, M.T., 2007. Cellulose acetate reverse osmosis membranes: optimization of preparation parameters. J. Appl. Polym. Sci. 103, 134-139.

Duong, Phuoc H.H., Chung, T.S., 2014. Application of thin film composite membranes with forward osmosis technology for the separation of emulsified oil-water. J. Membr. Sci. 452, $117-126$.

Frommer, M.A., Feiner, I., Kedem, O., Bloch, R., 1970. The mechanism for formation of "skinned" membranes: II. 
Equilibrium properties and osmotic flows determining membrane structure. Desalination 7, 393-402.

Gao, Y.B., Li, W.Y., Lay, Winson C.L., Coster, Hans G.L., Fane, Anthony G., Tang, C.Y., 2013. Characterization of forward osmosis membranes by electrochemical impedance spectroscopy. Desalination 312, 45-51.

Gao, Y.B., Wang, Y.N., Li, W.Y., Tang, C.Y., 2014. Characterization of internal and external concentration polarizations during forward osmosis processes. Desalination 338, 65-73.

Haddada, R., Ferjani, E., Roudesli, M.S., Deratani, A., 2004. Properties of cellulose acetate nanofiltration membranes. Application to brackish water desalination. Desalination 167, 403-409.

Halary, J.L., Noel, C., Monnerie, L., 1980. Analysis of transport phenomena in cellulose diacetate membranes. 4. Dependence of membrane desalination properties of annealing temperature - molecular analysis. Desalination 32, 65-76.

Hancock, N.T., Cath, T.Y., 2009. Solute coupled diffusion in osmotically driven membrane processes. Environ. Sci. Technol. 43, 6769-6775.

Hancock, N.T., Xu, P., Roby, M.J., Gomez, J.D., Cath, T.Y., 2013. Towards direct potable reuse with forward osmosis: technical assessment of long-term process performance at the pilot scale. J. Membr. Sci. 445, 34-46.

Hou, D.Y., Wang, J., Qu, D., Luan, Z.K., Ren, X.J., 2009. Fabrication and characterization of hydrophobic PVDF hollow fiber membranes for desalination through direct contact membrane distillation. Sep. Purif. Technol. 69, 78-86.

Idris, A., Ismail, A.F., Noordin, M.Y., Shilton, S.J., 2002. Optimization of cellulose acetate hollow fiber reverse osmosis membrane production using Taguchi method. J. Membr. Sci. 205, 223-237.

Jia, Z.J., Wang, B.G., Song, S.Q., Fan, Y.S., 2014. Blue energy: current technologies for sustainable power generation from water salinity gradient. Renew. Sust. Energ. Rev. 31, 91-100.

Jiao, B., Cassano, A., Drioli, E., 2004. Recent advances on membrane processes for the concentration of fruit juices: a review. J. Food Eng. 63, 303-324.

Kesting, R.E., 1990. The four tiers of structure in integrally skinned phase inversion membranes and their relevance to the various separation regimes. J. Appl. Polym. Sci. 41, 2739-2752.

Kim, I.C., Ahn, S.H., Jin, Y.S., Kim, B.S., Park, Y.I., Jegal, J., Lee, S.H., Kwon, Y.N., Rhee, H.W., 2013. Preparation of newly synthesized forward osmosis membrane. Desalin. Water Treat. 51, 5191-5195.

LaVan, D.A., McGuire, T., Langer, R., 2003. Small-scale systems for in vivo drug delivery. Nat. Biotechnol. 21, 1184-1191.

Li, G., Li, X.M., He, T., Jiang, B., Gao, C.J., 2013. Cellulose triacetate forward osmosis membranes: preparation and characterization. Desalin. Water Treat. 51, 2656-2665.

Liu, X., Qi, S.R., Li, Y., Yang, L., Cao, B., Tang, C.Y., 2013. Synthesis and characterization of novel antibacterial silver nanocomposite nanofiltration and forward osmosis membranes based on layer-by-layer assembly. Water Res. 47, 3081-3092.

McCutcheon, J.R., McGinnis, R.L., Elimelech, M., 2006. Desalination by ammonia-carbon dioxide forward osmosis: influence of draw and feed solution concentrations on process performance. J. Membr. Sci. 278, 114-123.

Mehta, G.D., Loeb, S., 1979. Performance of permasep B-9 and B-10 membranes in various osmotic regions and at high osmotic pressures. J. Membr. Sci. 4, 335-349.

Petrotos, K.B., Lazarides, H.N., 2001. Osmotic concentration of liquid foods. J. Food Eng. 49, 201-206.

Qin, J.J., Lay, W.C.L., Kekre, K.A., 2012. Recent developments and future challenges of forward osmosis for desalination: a review. Desalin. Water Treat. 39, 123-136.

Reuvers, A.J., Smolders, C.A., 1987. Formation of membranes by means of immersion precipitation: part II. the mechanism of formation of membranes prepared from the system cellulose acetate-acetone-water. J. Membr. Sci. 34, 67-86.

Reuvers, A.J., van den Berg, J.W.A., Smolders, C.A., 1987. Formation of membranes by means of immersion precipitation: part I. A model to describe mass transfer during immersion precipitation. J. Membr. Sci. 34, 45-65.

Rosenthal, U., Nechushtan, J., Kedem, A., Lancet, D., Frommer, M.A., 1971. An apparatus for studying the mechanism of membrane formation. Desalination 9, 193-200.

Sairam, M., Sereewatthanawut, E., Li, K., Bismarck, A., Livingston, A.G., 2011. Method for the preparation of cellulose acetate flat sheet composite membranes for forward osmosis-desalination using $\mathrm{MgSO}_{4}$ draw solution. Desalination 273, 299-307.

Schwarz, H.H., Richau, K., Hicke, H.G., 1987. Annealing effect in porous cellulose-acetate membranes. J. Membr. Sci. 34, 283-296.

Setiawan, L., Wang, R., Li, K., Fane, A.G., 2011. Fabrication of novel poly(amide-imide) forward osmosis hollow fiber membranes with a positively charged nanofiltration-like selective layer. J. Membr. Sci. 369, 196-205.

Shaffer, D.L., Werber, J.R., Jaramillo, H., Lin, S.H., Elimelech, M., 2015. Forward osmosis: where are we now? Desalination 356, 271-284.

Shibuya, M., Yasukawa, M., Takahashi, T., Miyoshi, T., Higa, M., Matsuyama, H., 2015. Effect of operating conditions on osmotic-driven membrane performances of cellulose triacetate forward osmosis hollow fiber membrane. Desalination 362, 34-42.

Strathmann, H., Kock, K., Amar, P., Baker, R.W., 1975. The formation mechanism of asymmetric membranes. Desalination 16, 179-203.

Su, J.C., Yang, Q., Teo, J.F., Chung, T.S., 2010a. Cellulose acetate nanofiltration hollow fiber membranes for forward osmosis processes. J. Membr. Sci. 355, 36-44.

Su, J.C., Zhang, S., Chen, H.Z., Chen, H.M., Jean, Y.C., Chung, T.S., 2010b. Effects of annealing on the microstructure and performance of cellulose acetate membranes for pressure-retarded osmosis processes. J. Membr. Sci. 364, 344-353.

Su, Y.C., Lin, L.W., 2004. A water-powered micro drug delivery system. J. Microelectromech. Syst. 13, 75-82.

Sun, B.H., 2011. Effect of thermodynamic and kinetic factors on structure and performance of asymmetric membrane formed via L-S phase inversion. Membr. Sci. Technol. 31, 1-11.

Venketeswari, P., Leong, O.S., Yong, N.H., 2014. Seawater desalination using forward osmosis process. J. Water Reuse Desal. 4, 34-40.

Wang, J., Sun, H.J., Gao, X.L., Gao, C.J., 2014. Enhancing antibiofouling performance of polysulfone (PSf) membrane by photo-grafting of capsaicin derivative and acrylic acid. Appl. Surf. Sci. 317, 210-219.

Wang, K.Y., Ong, R.C., Chung, T.S., 2010. Double-skinned forward osmosis membranes for reducing internal concentration polarization within the porous sublayer. Ind. Eng. Chem. Res. 49, 4824-4831.

Wang, Y., Lau, W.W.Y., Sourirajan, S., 1994. Effects of pretreatments on morphology and performance of cellulose-acetate (formamide type) membranes. Desalination 95, 155-169.

Wang, Y.Q., Ou, R.W., Wang, H.T., Xu, T.W., 2015. Graphene oxide modified graphitic carbon nitride as a modifier for thin film composite forward osmosis membrane. J. Membr. Sci. 475, 281-289.

Wasilewski, S., 1966. Microwave study of desalting membranes. Br. J. Appl. Phys. 17, 675.

Xie, M., Nghiem, L.D., Price, W.E., Elimelech, M., 2012. Comparison of the removal of hydrophobic trace organic contaminants by forward osmosis and reverse osmosis. Water Res. 46, 2683-2692. 
Yip, N.Y., Tiraferri, A., Phillip, W.A., Schiffrnan, J.D., Hoover, L.A., Kim, Y.C., Elimelech, M., 2011. Thin-film composite pressure retarded osmosis membranes for sustainable power generation from salinity gradients. Environ. Sci. Technol. 45, 4360-4369.

Young, T.H., Chen, L.W., 1993. Roles of bimolecular interaction and relative diffusion rate in membrane-structure control. J. Membr. Sci. 83, 153-166.

Zhao, H.Y., Qiu, S., Wu, L.G., Zhang, L., Chen, H.L., Gao, C.J., 2014. Improving the performance of polyamide reverse osmosis membrane by incorporation of modified multi-walled carbon nanotubes. J. Membr. Sci. 450, 249-256.
Zhao, P., Gao, B.Y., Xu, S.P., Kong, J.J., Ma, D.F., Shon, H.K., Yue, Q.Y., Liu, P., 2015. Polyelectrolyte-promoted forward osmosis process for dye wastewater treatment - exploring the feasibility of using polyacrylamide as draw solute. Chem. Eng. J. 264, 32-38.

Zhu, Z.X., Matsuura, T., 1991. Discussions on the formation mechanism of surface pores in reverse osmosis, ultrafiltration, and microfiltration membranes prepared by phase inversion process. J. Colloid Interface Sci. 147, 307-315. 